\title{
A Surfactant - A New Line of Defense against Plaque
}

\author{
Priya Mehta ${ }^{1}$, Neha Saini ${ }^{2}$, Varun Saini ${ }^{3}$, Toni shori ${ }^{4}$ \\ ${ }_{184}$ (Department of Periodontics, VSPM dental college Nagpur, India) \\ ${ }^{2}$ (Department of Periodontics, Jaipur dental college Jaipur, India) \\ ${ }^{3}$ (Department of Prosthodontics, RR dental college Udaipur, India)
}

\begin{abstract}
Surfactant is a surface acting agent, usually organic compound that are amphiphilic. Aim of the study was to compare plaque inhibition property of a surfactant rich dentifrice \& a commercially available dentifrice.

20 patient of generalized chronic gingivitis in age group 18-30 yr. Full mouth ultrasonic scaling was done \& vertical brushing technique demonstrated \& advocated. Patients were divided into 2 groups, paste A (delmopinol) \& B (sodium lauryl sulfate). Plaque indices were taken before scaling, after scaling, after 7 days \& 14 days. Inter comparison between the 2 groups showed that plaque score was lower in group A when compared with group B at $7 \& 14$ days. Delmopinol hydrochloride \& sodium lauryl sacrocinate is found to be more potent in plaque inhibition as compared to sodium lauryl sulfate alone.
\end{abstract}

Keywords: Delmopinol hydrochloride, sodium lauryl sacrocinate, sodium lauryl sulfate, chronic gingivitis, plaque inhibition.

\section{Introduction}

Plaque control is removal of microbial plaque \& the prevention of its accumulation on the teeth $\&$ adjacent gingival tissue. It also deals with the prevention of calculus formation. Chemical agents used for plaque control can influence plaque quantity \& qualitatively via a number of processes. The action of chemical agents could fit into 4 categories, antiadhesive, antimicrobial, antiplaque, antipathogenic. Vehicle for delivery of chemical agents into the mouth for plaque control are: tooth paste, mouth rinses, sprays, irrigators, chewing gum, varnishes. Chemical plaque control agents can be classified into $1^{\text {st }}$ generation which include antibiotics, phenols, quaternary $; 2^{\text {nd }}$ generation include bisbiguanides- chlorhexidine ; $3^{\text {rd }}$ generation include delmopinol ${ }^{1}$. Delmopinol hydrochloride is surface active agent (surfactant) is defined as an organic chemical that when added to liquid changes that properties of that liquid at an interface. Mode of action of delmopinol likely to be based on physicochemical mechanism rather than an antimicrobial activity.

Anionic detergents are widely used in dentifrices \& mouth rinse. They are used for their foaming capacity and their emulsifying \& cleansing properties. The most common anionic detergent used in dentifrices is sodium lauryl sulfate(SLS).Sodium lauryl sacrosinate is mild, biodegradable ionic surfactant derived from fatty acid and sarcosine ${ }^{2}$.The aim of the study was to compare plaque inhibition property of a surfactant rich dentifrice \& a commercially available dentifrice.

\section{Material And Method}

The study included 20 patients in the age group of 18-30 yrs with chronic generalized gingivitis who were selected from the outpatient department of periodontics. The following criteria were observed in the enrolment of the patients : (1) with Gingival index ${ }^{3}$ (SILNESS \& LOE 1964) and probing depth $\leq 3 \mathrm{~mm} ;$; 2 ) not presently using any mouthwash ; (3) with no systemic disease ;(4) who had not undergone periodontal therapy in past 6 month ; (5) pregnant and lactating women were excluded. An ethical committee approval was sought before commencement of the study .

\subsection{Subjects}

Patients were screened for gingival bleeding and pocket depth. Subjects were explained about the nature of the study and informed consent was taken .

\subsection{Group division}

The selected patients were grouped as :

Group A : 10 patients who used paste A containing sodium lauryl sacrocinate \& delmopinol HCL $0.2 \%$

Group B : 10 patient who used paste B containing only sodium lauryl sulphate $1.5 \%$.

Full mouth scaling was done \& vertical brushing technique was demonstrated \& advocated. Plaque assessment was done by Turesky- Gilmore- Glickman modification of the Quigley and Hein plaque index $1970^{4}$. Plaque indices were recorded before \& after scaling \& after $7 \& 14$ days. 


\section{Results}

A total of 20 subject (12 female \& 8 males; age range 18-30 yr) participated in the study. No adverse events were reported or soft tissue pathology noted. For both paste A and paste B, when intra comparisons were done at $7 \& 14$ days (graph no.1), the result was statistically significant $(\mathrm{p}<.05)$. Paired t test was used(table no 1).

Table No. 1 Showing mean change + SD for paste A and paste B at $7 \& 14$ days.

\begin{tabular}{|c|c|c|c|c|c|}
\hline \multirow[t]{2}{*}{ Paste } & \multicolumn{2}{|l|}{ Mean $\pm \mathrm{Sd}$} & \multirow[t]{2}{*}{ Mean change $\pm \mathrm{Sd}$} & \multirow[t]{2}{*}{ P-value } & \multirow[t]{2}{*}{ Significance } \\
\hline & $7^{\text {th }}$ day & $14^{\text {th }}$ day & & & \\
\hline $\mathrm{A}$ & $1.37 \pm 0.46$ & $0.43 \pm 0.41$ & $0.94 \pm 0.63$ & $<.05$ & Sig \\
\hline B & $1.86 \pm 0.31$ & $1.41 \pm 0.55$ & $0.45 \pm 0.33$ & $<.05$ & Sig \\
\hline
\end{tabular}

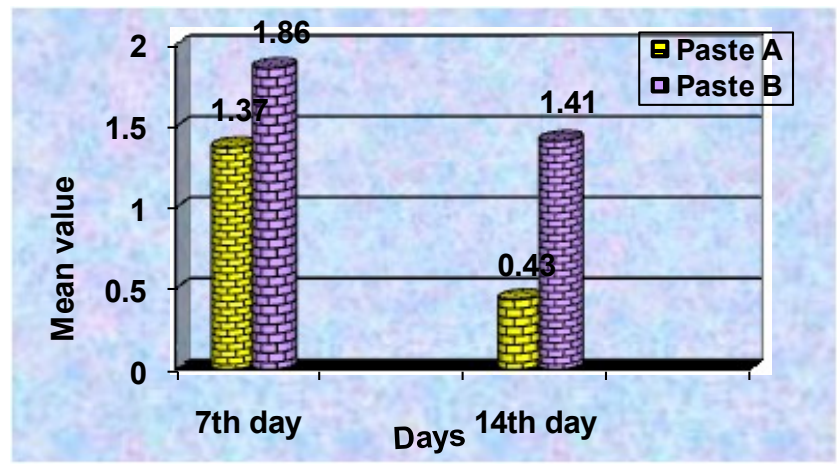

Graph No.1 Showing plaque index mean value at 7 day \& 14 day.

\section{Discussion}

The present study compared paste A containing delmopinol and sodium lauryl sacrocinate and paste B containing sodium lauryl sulphate for plaque inhibition. In Group A significant reduction in plaque index was observed $(\mathrm{p}<0.05)$, which showed that delmopinol hydrochloride exerts an inhibitory effect on formation of dental plaque. Delmopinol acts by disrupting the existing plaque matrix by reducing the viscosity of glucans \& loosening the cohesive properties. It slows the formation of salivary pellicle on clean surface, also reduces the adherence of pioneer bacteria to salivary pellicle on tooth \& gingival surface ${ }^{5}$.

Sodium lauryl sacrocinate is an anionic surfactant which reduces the $\mathrm{pH}$ drop observed in dental plaque after application of sucrose, there by slightly lowering the cariogenic effect of plaque. ${ }^{2}$ It resisted removal from the plaque over a period of several hours, decreased the rate of acid formation in the plaque that has been removed from teeth after the mouth has been rinsed for 30 seconds with $50 \%$ sucrose solution, and also to some extent inhibit glycolysin in saliva sediments.

The present study goes in hand with previous studies ${ }^{5}$ in which plaque dissolving property of delmopinol hydrochloride in vivo is in line with in vitro data suggesting that substance interferes with the plaque matrix by reducing the cohesion with plaque to the tooth surface. The present findings are also in line with previous observations that even mineralized deposits may be more loosely attached to the teeth when amino alcohols are used as anti- plaque agent ${ }^{6}$.

The application of delmopinol hydrochloride onto the tooth surface during the 0 to 7 days seem to have altered the pre requisites for plaque formation during the second phase, possibly by making the pellicle surface less prone to colonization by oral bacteria.

Sodium lauryl sulphate (SLS) is an anionic surfactant used in many consumer products , It has a variety of functions which provide both sensory and therapeutics benefits of toothpaste. The sensory function include detersive and emulsifying properties of SLS which imparts a foaming sensation with a perception of cleaning. These properties are thought to increase consumer appeal and compliance for the use of dentifrices. The therapeutic function of SLS is its surface active properties. ${ }^{7}$ Studies have suggested that SLS binds to bacterial proteins, causing an interference of bacterial attachment to tooth surfaces thus reducing formation of bacterial plaque $^{8}$. Studies have shown a relationship between anti-microbial activity and the presence of SLS in the mouth ${ }^{9}$.

Adverse effects associated with SLS are that it increases epithelial permeability via denaturation of the mucin layer of the oral mucosa. This property was implicated in an increased incidence of recurrent aphthous ulcerations $(\mathrm{RAU})^{10}$. 
Thus SLS also has beneficial effect of reducing plaque index but to a lesser extent when compare with delmopinol.

Inter comparison between two group exhibited paste $\mathrm{A}$ found to be more effective in reducing plaque index as delmopinol reduce the cohesive forces within glucan containing plaque and sodium lauryl sacrocinate reduce the $\mathrm{pH}$ of the dental plaque.

\section{Conclusion}

Delmopinol Hydrochloride and Sodium lauryl sacrocinate are found to be more potent in plaque inhibition as compared to Sodium lauryl sulfate alone.

\section{References}

[1] Lindhe, Clinical periodontology and implant dentistry ( place of publication \& publisher ) $5^{\text {th }}$ edition

[2] H J Busscher \& L.V. Evans, Oral Biofilms and Plaque Control, Taylor \& Francis, 19-Feb-1999,348 pages.

[3] Niederman R, Triclosan-containing toothpastes reduce plaque and gingivitis ,Evid Based Dent. 2005;6(2):33.

[4] Triratana, Terdphong; Rustogi, Kedar, N.; Volpe, Anthony, R.; Devizio, William; Petrone, Margaret; Giniger, Martin, 2002: Clinical effect of a new liquid dentifrice containing triclosan/copolymer on existing plaque and gingivitis. Journal of the American Dental Association 133(2): 219-225)

[5] Rundegren J, Simonsson T, Petersson L, Hansson E. Effect of delmopinol on the cohesion of glucan-containing plaque formed by Streptococcus mutans in a flow cell system. J Dent Res 1992; 71:1792-1796.)

[6] Matsson L, Kling B, et al., The effect of octapinol on dento-gingival plaque and development of gingivitis. Long term studies in dogs. Journal of periodontal research . 18 . 1983, 438-444.

[7] Fakhry-Smith S, Din C, Nathoo SA, Gaffar A, Clearance of sodium lauryl sulphate from the oral cavitv. J Clin Periodontol . 24 . $1997,313-317$

[8] Pader, M., Oral hygiene products and practices. Cosmetic Science \& Technology Series . 6. 1998, 419-526.

[9] Jenkins, S., Addy, M., \& Newcombe, R. Triclosan and sodium lauryl sulphate mouth rinses Effects of 4-day plaque regrowth. Journal of Clinical Periodontology .18 . 1991, 145-148.

[10] Barkvoll,'P \& Rolla, G. Possible effects of sodium lauryl sulphate (SLS) on the oral mucosa. Journal of Dental Research . 68. 1989, 